\title{
MARX E HEGEL: RUPTURA E CONTINUIDADE NO MÉTODO DIALÉTICO ${ }^{1}$
}

\author{
Roberto Robaina $^{2}$
}

\begin{abstract}
Resumo:
Este artigo trata da relação entre Marx e Hegel. Aborda qual a essência da ruptura entre os autores e qual o eixo em torno do qual se pode definir a existência de continuidade. O tema central é a dialética e o método. Recorre ao testemunho de Marx acerca da sua diferença filosófica com Hegel. Parte da reivindicação do materialismo como corrente oposta ao idealismo, do qual Hegel era o principal expoente. A partir daí nos concentramos na discussão sobre a obra principal de Marx, O Capital, e buscamos mostrar a relação entre a escolha de Marx acerca de como começar sua exposição e o método de Hegel. Nosso eixo foi a categoria inicial de Marx, a mercadoria, e estabelecemos a analogia entre as determinações da mercadoria e as categorias iniciais do primeiro livro da Ciência da Lógica, a Doutrina do Ser, afirmando a importância das contradições iniciais para a compreensão do desenvolvimento do movimento do capital.
\end{abstract}

Palavras-Chaves: Ser; Mercadoria; Método; Hegel; Marx.

\section{MARX AND HEGEL: RUPTURE AND CONTINUITY IN THE DIALECTICAL METHOD}

\begin{abstract}
:
This article deals with the relationship between Marx and Hegel. It addresses the essence of the rupture between the authors and the axis around which the existence of continuity can be defined. The central theme is dialectics and method. It uses Marx's testimony about his philosophical difference with Hegel and shows materialism as a current opposed to idealism, of which Hegel was the main exponent. From there, we focus on the discussion of Marx's main work, Capital, and explains the relationship between Marx's choice of how to begin his exposition and Hegel's method. We focus on Marx's initial category, the commodity, and establish an analogy between the determinations of the commodity and the initial categories of the first book on the Science of Logic, the Doctrine of Being, establishing the importance of the initial contradictions for understanding the development of the movement of capital.
\end{abstract}

Keywords: To be; Merchandise; Method; Hegel; Marx.

Introdução

Marx na juventude foi um hegeliano, ativo entre os chamados hegelianos de esquerda. Mas o foi por pouco tempo. Entre os marxistas se estabeleceu uma grande polêmica acerca da influência de Hegel em sua obra. É um fato biográfico, não questionado, que o Capital é a sua obra decisiva, a qual dedicou a maior parte de sua vida intelectual. Não há discussão que foi sua obra madura. Junto com o Manifesto Comunista é seu aporte universal e histórico mais decisivo e a apresentação mais desenvolvida de seu pensamento. É nela que devemos apreciar o peso e a influência de Hegel.

1 O presente artigo foi elaborado a partir do conteúdo de Marx e o Núcleo Racional da Dialética De Hegel, livro da minha autoria, publicado em 2013.

2 Graduado em História, mestre e doutor em Filosofia pelo Programa de Pós-Graduação em Filosofia da Pontifícia Universidade Católica. Dirigente nacional do Partido Socialismo e Liberdade - PSOL e vereador no Município de Porto Alegre-RS (BRASIL). carlosrobaina@uol.com.br 
Pois é no posfácio de O Capital que Marx afirma que seu método é o oposto de Hegel. "Meu método dialético, por seu fundamento, difere do método hegeliano, sendo a ele inteiramente oposto" (MARX, 1987, p.16). Comenta neste prefácio, de 1873, que tratou de Hegel, criticando o que sua obra tem de mistificação, há 30 anos atrás, quando Hegel ainda estava na moda. Marx estava se referindo e nos remetendo a seu livro a "Sagrada Família", obra escrita em conjunto com Engels e publicada em 1844, um dos poucos livros deste período da vida de Marx efetivamente publicados, dos tantos que foram escritos mas não receberam a forma acabada - tais como os Manuscritos, A Ideologia Alemã, A Crítica à filosofia do direito- a qual Marx tanto exigia de si mesmo antes de entregar ao domínio público suas elaborações.

Ruptura e continuidade: Sagrada Família e O Capital

Na Sagrada Família, Marx postulara o materialismo francês como base do comunismo e do Iluminismo como movimento que não apenas encabeçou a luta contra as instituições políticas existentes e "contra a religião e a teologia imperantes, mas também e na mesma medida uma luta aberta e marcada contra a metafísica do século VVIII e contra toda a metafísica, especialmente contra a de Descartes, Malebranche, Spinoza e Leibniz" (MARX et al, 2011, p 144), metafísica a qual Marx acusará o idealismo alemão, e Hegel em particular, de restaurar no século XIX. Reivindicará a Grã Bretanha como o lugar de nascimento do materialismo e do método científico, a corrente da qual se declara seguidor. A ciência experimental moderna iniciado por Bacon e seguido por Hobbes é a ciência da experiência e "consiste em aplicar o método racional ao que o sentido nos oferece" (idem, p.147) resumida por Marx da seguinte forma:

\footnotetext{
A indução, a análise, a comparação, a observação, e a experimentação são as principais condições de um método racional. Entre as qualidades inatas à matéria, a primeira e primordial é o movimento, não apenas enquanto movimento mecânico e matemático, mas também, e mais ainda, enquanto impulso, espírito de vida, força de tensão e tormento - para empregar a expressão de Jacob Bohme - da matéria. As forças primitivas desta são forças essências vivas, individualizadoras, inerentes a ela, e que produzem as diferenças específicas (MARX et al, 2011, p 147).
}

Marx resumira aqui seu próprio método de investigação. Mais tarde, como veremos, irá diferenciar o método de investigação do método de exposição. O continuador de Bacon e Hobbes foi Locke, com seu "Ensaio sobre a origem do entendimento humano", e a

\begin{tabular}{|l|l|l|l|l|}
\hline Qevista Dialectus & Ano 9 & n. 18 & Outubro 2020 & p. 86-101 \\
\hline
\end{tabular}


partir de então os franceses com Condillac e Helvétius, em suma os enciclopedistas mais famosos dotaram, nas palavras de Marx, o materialismo inglês "de espírito, de carne e de sangue (idem, p.148). Marx não desprezara os aportes científicos de Descartes, que separou a física da metafisica e que no seu materialismo permitiu o desenvolvimento da ciência da natureza, enquanto a tendência materialista francesa dos enciclopedistas, herdeira do materialismo inglês, desembocou diretamente no socialismo e no comunismo. Está mais do que claro que Marx, em sua obra mais trabalhada, no próprio posfácio de O Capital, nos remete a sua obra no qual se filia a corrente oposta ao idealismo na história da filosofia. É seu período em que reivindica as obras de Feurbach, a "Filosofia do futuro" e "Essência da fé", ambas críticas a Hegel. Em carta de Marx a Feurbach, escrita em Paris em 11 de agosto de 1844 chega a dizer: "em ditas obras, você, não sei se com intenção, há dado ao socialismo uma base filosófica" (MARX, 1969, p.20). Assim, diante do idealismo e da ideia tão em voga na época de que o espírito domina o mundo, de que a ideia forma a realidade, o pensamento determina o ser, Marx afirma a filosofia materialista, o primado da matéria sobre o espírito, do ser sobre o pensamento. Nas suas teses provisórias para a reforma da Filosofia, Feuerbach explanava:

\footnotetext{
A filosofia hegeliana é a supressão da contradição entre pensar e ser, como em especial Kant a expressou, porém, observe-se bem, somente a supressão desta contradição - dentro de um elemento, dentro do pensar. Em Hegel, o pensamento é o ser; o pensamento é o sujeito, o ser é o predicado (FEUERBACH, 1969, p. 46).
}

E em seguida completa: "A verdadeira relação do pensar com o ser é unicamente esta: o ser é o sujeito e o pensar o predicado. O pensar provém do ser, porém não o ser do pensar" (FEUERBACH, 1969, p. 47). O desdobramento destas teses em Marx foi sua definição de que o ser social é que determina a consciência, não o contrário. Este ponto de ruptura com Hegel foi determinante em toda a compreensão de Marx. Estes bases fundamentais parecem mostrar a distância total de Marx em relação a Hegel.

$\mathrm{O}$ assunto estaria encerrado para aqueles que consideram a relação de Marx com Hegel uma relação cuja essência é a ruptura. Mas as coisas não são tão simples. Marx reivindica tal ruptura, mas aceita que representa também uma continuidade. No mesmo posfácio supracitado, linha seguida a reivindicação da Sagrada Família, Marx rechaça aos que hoje, passada a moda de Hegel, o tratam como um cão morto. Vai adiante e se declara discípulo. E esclarece que a mistificação que a dialética sofreu nas mãos de Hegel não o

\begin{tabular}{|c|c|c|c|c|}
\hline Rovista Dialectus & Ano 9 & n. 18 & Outubro 2020 & p. $86-101$ \\
\hline
\end{tabular}


impediu de ser quem primeiro expôs as formas gerais do movimento de forma ampla e consciente. É um notável reconhecimento. Vale ser dito que logo após reivindicar a Feurbach, ainda na década de quarenta do século XIX, Marx escreveu as suas 11 teses, muito conhecidas sobre os limites do materialismo de Feurbach, afirmando que o defeito de todo o materialismo anterior, incluindo o de Feurbach, é que só concebe o objeto, a realidade, a sensorialidade, sob a forma de objeto (objekt) ou de contemplação, porém não como atividade sensorial humana, como prática, não de um modo subjetivo" (Tese I). O idealismo desenvolveu este lado ativo, reconhece Marx em 1845.

No posfácio Marx faz seu reconhecimento de que a dialética na sua forma racional - ou seja posta de cabeça para cima - e portanto negando o invólucro místico de Hegel causa horror à burguesia e é essencialmente crítica e revolucionária na medida em que sua concepção do existente aprende o caráter transitório do existente e as formas em que se configura seu devir. Apesar disso Marx não explica aí como desenvolve seu método, se limitando a afirmar que o método de exposição difere do método de pesquisa, sendo o segundo o apoderamento da matéria, de seus pormenores, análise do desenvolvimento das suas diferentes partes e as conexões entre elas. A descrição deste movimento real deve ser feita depois, espelhada num plano ideal. Se referindo a Hegel, é só no plano da descrição, confessa Marx "no capítulo sobre teoria do valor, joguei, várias vezes, com seus modos de expressão peculiares" (MARX, 1987, p.16).

Aqui já é fundamental ter em conta o que significa o modo de exposição. Não se trata de um discurso. Marcos Müller define como o assunto era tratado por Hegel:

Exposição é, também, um conceito central da dialética especulativa de Hegel. A Ciência da Lógica se apresenta como a exposição sistemática das categorias do pensamento puro enquanto formas de concepção da realidade, com o intuito de fundar o próprio conceito de ciência (filosófica) e de método. Ela pretende, assim, justificar o seu único pressuposto, o de que a razão, especificamente, o conceito enquanto ideia, tem em si a força infinita de sua auto-realização (Müller,1982, p.3).

A leitura e o estudo atento de O Capital revela mais do que um jogo "com os modos de expressão peculiares" de Hegel e revela muito do núcleo racional da dialética, que teve em Hegel "quem primeiro expôs as formas gerais do movimento de forma ampla e consciente". (idem, p.17.).

Na Ciência da Lógica, obra em que Hegel ensina seu método, deixa claro que somente quando algo tem em si mesmo uma contradição se move por si mesmo, tem impulso

\begin{tabular}{|l|l|l|l|l|}
\hline Qevista Dialectus & Ano 9 & n. 18 & Outubro 2020 & p. 86-101 \\
\hline
\end{tabular}


e movimento e que apenas com o método dialético se apreende o fenômeno em seu desenvolvimento, em sua passagem de um estado a outro, relacionando forma e conteúdo e tratando sempre de ligar a lógica ao conteúdo do processo, assimilando precisamente o movimento interno de seu conteúdo e seu caráter relacional.

O método não é distinto de seu objeto e conteúdo, pois é o próprio conteúdo, a dialética que este encerra em si, que o impulsiona para frente. É por isso que nenhuma exposição pode ser considerada científica se não seguir o curso deste método; e se não se adapta ao seu ritmo sensível, pois este é o da própria coisa (HEGEL, 1968, p. 50).

Em outras palavras, Hegel não aceitava a ideia de um método que fosse exterior ao movimento objetivo das coisas. "Só o método consegue domar o pensamento e levá-lo à coisa e aí o reter", disse no prefácio da segunda edição da pequena lógica (HEGEL, 1969, p. 45). Marx utilizou com muita força este método, que, segundo Hegel, nada mais é do que a forma do autodesenvolvimento do seu conteúdo, a exposição do movimento lógico do conteúdo, da coisa mesma. Trata-se de uma retomada de Hegel para a compreensão do objeto de estudo de Marx, a saber, o modo de produção capitalista e suas formas do movimento. Assim, esclarece novamente Müller,

\footnotetext{
Dialética significa em O Capital primeiramente e, também, predominantemente, o "método/exposição" crítica das categorias da economia política, o método de "desenvolvimento do conceito de capital" a partir do valor, presente na mercadoria, enquanto ela é categoria elementar da produção capitalista que contém o "germe" das categorias mais complexas. O conceito fundamental, aqui, para o Marx crítico da economia política, é o da "exposição", método de "exposição", que designa o modo como o objeto, suficientemente aprendido e analisado, se desdobra em suas articulações próprias e como o pensamento as desenvolve em suas determinações conceituais correspondentes, organizando um discurso metódico (Müller,1982,p.2).
}

Os argumentos que seguem estão focados na discussão sobre como Marx decide finalmente iniciar sua exposição da obra O Capital. Não iremos, portanto, abordar o desenvolvimento das categorias econômicas de Marx em O Capital e sua possível analogia com a Lógica de Hegel. Nos limitaremos ao começo.

A dialética em $O$ Capital - Por onde começar?

Lênin disse certa vez que não se podia entender $O$ Capital sem ter lido e estudado toda a Lógica de Hegel. Completou dizendo que nenhum marxista o havia entendido. Embora

\begin{tabular}{|l|l|l|l|l|}
\hline Qovista Dialectus & Ano 9 & n. 18 & Outubro 2020 & p. 86-101 \\
\hline
\end{tabular}


este aforismo contenha certo exagero, não há dúvida de que a estrutura metodológica desenvolvida por Hegel foi muito útil na elaboração de Marx, e ajuda muito a entender as relações sociais capitalista enquanto uma totalidade em movimento, por um processo de contradições cada vez maiores e determinações mais completas; um processo de automovimento.

Enquanto em Hegel a lógica é do conceito, em Marx se trata da lógica do processo social de produção capitalista. Ao examinar $O$ Capital, se percebe que de fato o tratamento dado por Marx, sobretudo nos primeiros capítulos do livro, tem uma estrutura que se apresenta como um sistema organizado de categorias, em que a exposição parte de uma categoria inicial mais simples a partir da qual as demais categorias podem ser derivadas. As contradições e tensões da categoria inicial vão chamando para o sistema outras categorias e conceitos, que se articulam num todo estruturado cada vez mais complexo.

Em $O$ Capital Marx tratou das leis do modo de produção capitalista, as leis de seu nascimento, desenvolvimento e crise. Este foi seu objeto. E aqui aplicou o conceito de contradição como motor do desenvolvimento, como a lógica interna do movimento econômico. Para Marx as contradições de classes, no caso do modo de produção capitalista, eram acompanhadas por uma contradição no interior do próprio funcionamento do sistema do capital. Marx deixa claro que um dos seus precursores na economia, certamente o principal deles, David Ricardo, também partia das contradições. E via nelas um caráter natural. Mas a burguesia não pode levar adiante este raciocínio. Eram os anos 20 e 30 do século XIX. Depois disso, a burguesia conquistara poder político na França. Na Inglaterra, a luta de classes se intensificou; a verdade passou a deixar de ser importante para a classe dominante. Soou o dobre de finados da ciência econômica burguesa, nas palavras de Marx. A partir de então a economia burguesa assumiu a ideologia da harmonia, de que o modo de produção capitalista, além de natural, tende ao equilíbrio e à estabilidade.

Vale ressaltar que, segundo Marx, a economia tem leis, mas são válidas por períodos determinados da evolução social. A regularidade econômica é então datada. Nisso se diferenciava claramente de Ricardo, para quem as leis eram naturais e eternas. Daí a enorme importância da dialética de Hegel. Em sua racionalidade, a dialética afirma o existente e ao mesmo tempo sua negação.

A questão posta por Marx foi por onde deveria se começar para expor esta lógica interna. Qual categoria a partir da qual a estrutura do todo se articularia num processo de desenvolvimento das contradições? Marx resolveu começar sua obra pela análise da

\begin{tabular}{|l|l|l|l|l|}
\hline Qenista Dialectus & Ano 9 & n. 18 & Outubro 2020 & p. 86-101 \\
\hline
\end{tabular}


mercadoria. Para ele o começo era fundamental para quem quisesse compreender a ciência.

Deixa claro esta questão no prefácio, onde assinala também a importância da abstração para o desenvolvimento do pensamento e a apreensão do real, do concreto como concreto pensado. Suas palavras eram estas: "Todo o começo é difícil em qualquer ciência".

\begin{abstract}
Por isso, o Capítulo I é o que oferece maior dificuldade à compreensão, notadamente a seção que contém a análise da mercadoria. Nele procurei expor, com maior clareza possível, o que concerne especialmente à análise da substância e da magnitude do valor. A forma do valor, a qual tem no dinheiro sua figura acabada, é muito vazia e simples. Apesar disso, tem o espírito humano, há mais de dois mil anos, tentado em vão devassá-la, embora conseguisse analisar, pelo menos com aproximação, formas muito mais complexas e ricas de conteúdo. Por quê? Porque é mais fácil estudar o organismo, como um todo, do que suas células. Além disso, na análise das formas econômicas, não se pode utilizar nem microscópio nem reagentes químicos. A capacidade da abstração substitui esses meios. A célula econômica da sociedade burguesa é a forma mercadoria, que reveste o produto do trabalho, ou a forma de valor assumida pela mercadoria. Sua análise parece, ao profano, pura maquinação de minuciosidades. Trata-se, realmente, de minuciosidades, mas análogas àquelas da anatomia microscópica (MARX, 1985, p. 16).
\end{abstract}

Aqui fica visível também como era rica a colaboração de Marx e Engels. Parece óbvio que a consideração de Marx sobre o estudo da célula teve inspiração em Engels. Bem antes da conclusão de O Capital, o velho amigo escreveu para Marx uma carta entusiasmada:

O microscópio conduziu a resultado ainda mais importante que a química; a principal coisa que revolucionou na fisiologia enquanto um todo, e que fez possível pela primeira vez a fisiologia comparada, é o descobrimento da célula (nas plantas por Schleiden e nos animais por Schwann, ao redor de 1836). Tudo é célula. A célula é o ser em-si-mesmo de Hegel, e seu desenvolvimento segue exatamente o processo hegeliano, terminando na Ideia, isto é, em cada organismo completo (MARX et al, 1987, p. 100).

Em Marx a célula passou a ser a mercadoria no interior da qual seu desenvolvimento leva até ao capital, isto é, o equivalente à ideia em Hegel, caso queiramos manter a analogia de Engels. A importância desta descoberta não é menor. Marx ficou muito tempo pensando antes de decidir por onde começar. Encontrar no modo de produção capitalista o equivalente da célula na biologia somente foi possível com o aprendizado anterior do ser em si de Hegel. O conceito do ser em si em Hegel foi muito bem explicado pelo próprio em sua monumental história da Filosofia.

O que agora se nos apresenta na evolução é que deve existir algo que é desenvolvido, logo algo envolvido, o gérmen, a aptidão, a potência, é o que Aristóteles chama dynamis, isto é a possibilidade (mas a possibilidade real, não, por certo, uma possibilidade superficial), ou, como é chamada, e em si, aquilo que é em si e só imediatamente assim (HEGEL, 1976, p. 33).

\begin{tabular}{|l|l|l|l|l|}
\hline Qevista Dialectus & Ano 9 & n. 18 & Outubro 2020 & p. 86-101 \\
\hline
\end{tabular}


E segue na mesma explicação definindo que se trata ainda de uma abstração. E é isso mesmo que Marx explica ao começar pela mercadoria, a necessidade de começar pelo mais simples, mas que tem no seu interior as determinações da totalidade. Hegel diz:

Do que é em si tem-se ordinariamente a alta opinião de que é o verdadeiro. Aprender a conhecer Deus e o mundo, quer dizer: conhecê-los em si. Mas o que é em si, não é ainda o verdadeiro, mas o abstrato; é o germe do verdadeiro, a aptidão, o ser em si do verdadeiro. É alguma coisa simples, sem dúvida, o que contém, o que possui as qualidades do múltiplo em si, mas na forma de simplicidade, um conteúdo que ainda está envolto. (HEGEL, 1976, p. 33)

A importância do conceito de "ser em si" e da dinâmica nele implicada é ainda reforçada: Um exemplo disso é o germe. O germe é simples, quase um ponto. Até por meio do
microscópio, descobre-se pouca coisa nele. Mas este simples contém todas as
qualidades da árvore. No germe está contida toda a árvore, seu tronco, seus ramos,
suas folhas, suas cores, o cheiro, o sabor etc. Entretanto, este simples, o germe, não é
a árvore. Esta diversidade ainda não existia. É essencial saber isto: que algo que
contém uma diversidade em si, mas que ainda não existia por si (HEGEL, 1976, p.
33).

É óbvio que Marx teve como alicerce estas definições quando sustentou que a mercadoria era a célula da produção burguesa, e no seu interior encontram-se todas as determinações do capital, mas que a mercadoria não é ainda o capital.

Deduzir todo o capitalismo a partir da estrutura da mercadoria e da necessidade que o trabalho provado tem de se representar como trabalho social não é um procedimento "filosófico" que pudesse ser substituído por outros procedimentos porventura mais "potentes". Trata-se antes de um procedimento que reproduz a verdadeira estrutura da sociedade mercantil desenvolvida (JAPPE, 2006, p. 174).

Jappe corretamente sustenta que captar os "conceitos essências da sociedade mercantil permite compreender-lhe o mecanismo sem ter que lhe examinar todos os pormenores empíricos" (JAPPE, 2006, p. 174). Concordo com Jappe e por isso há de fato uma estrutura lógica em O Capital, não apenas uma exposição histórica. Mas vejamos um pouco sobre a definição deste conceito simples, este início de Marx, a mercadoria. Ao tratar este conceito, a analogia que salta à vista é com o primeiro livro da Lógica de Hegel, isto é, a Doutrina do Ser.

\begin{tabular}{|c|c|c|c|c|}
\hline Rovista Dialectus & Ano 9 & n. 18 & Outubro 2020 & p. $86-101$ \\
\hline
\end{tabular}


A Mercadoria em O Capital e a Doutrina do Ser em Hegel

A doutrina econômica de Marx começa definindo que a produção capitalista é a produção generalizada de mercadorias. Em primeiro lugar a mercadoria precisa ter utilidade. A utilidade é o valor de uso que os trabalhadores produzem, a saber, objeto útil para atender às diversas necessidades humanas e base material da riqueza em qualquer sociedade. Mas no capitalismo o valor de uso produzido tem como objetivo ser vendido, isto é, um produto para ser trocado. Isso quer dizer que a mercadoria pressupõe o valor de troca, a produção para ser vendida no mercado.

Ao falar de valor de uso e valor de troca nos remetemos aos conceitos tão importantes em Hegel: qualidade e quantidade. O valor de uso envolve qualidade; sua produção demanda um determinado tipo de trabalho, com determinada capacidade técnica, específica, que produz um objeto determinado, com determinada utilidade, com uma qualidade concreta. Seja um carro, um computador, ou, para usar o exemplo típico de Marx, um casaco. Mas a mercadoria é produzida para ser trocada. Para a produção de valor de troca o valor de uso é apenas sua substância material. O valor de troca envolve quantidade, e revela-se, segundo Marx, na relação de troca, relação quantitativa entre valores de uso de espécies diferentes, na proporção em que se trocam as mercadorias sujeitas a mudanças constantes no tempo e no espaço.

Mas como estabelecemos a relação de troca, a proporção entre os produtos no mercado? É lógico que para serem trocados os valores de troca precisam ser comparados, e, portanto, ter algo em comum. Não pode ser sua utilidade concreta. Não há porque trocar valores de qualidade igual. Não tem porque se trocar uma gravata por outra gravata igual. $\mathrm{O}$ certo é que alguém vende algo de que não tenha necessidade imediata e compra aquilo que tem necessidade.

Assim, a mercadoria que é um não valor de uso para o proprietário, que detém a mercadoria para ser vendida, é valor de uso para o não proprietário que necessita comprar a mercadoria. Logo, sua qualidade comum não pode ser seu valor de uso concreto, já que a utilidade diferente delas é o que motiva a troca. Marx chega à conclusão de que a qualidade que as mercadorias têm em comum, o que permite que as mesmas sejam comparadas, comensuráveis, é ser produto do trabalho humano, dispêndio humano de músculos, nervos, inteligência, energia.

\begin{tabular}{|l|l|l|l|l|}
\hline Govista Oialectus & Ano 9 & n. 18 & Outubro 2020 & p. 86-101 \\
\hline
\end{tabular}


Chegamos ao conceito fundamental de Marx: o conceito de valor. O valor é o trabalho humano despendido para produzir mercadorias. É a partir dele que se pode comparar mercadorias diferentes. Mas qual a medida do valor? A mesma é medida em tempo de trabalho. É este tempo de trabalho que se expressa, que se manifesta no valor de troca da mercadoria. O valor de troca de uma mercadoria é medido em tempo de trabalho. A mercadoria é um determinado valor cuja medida é o tempo de trabalho humano gasto em sua produção, mas não um tempo particular, específico, de cada mercadoria. Marx explica que não é qualquer tempo, mas o tempo de trabalho socialmente necessário, isto é, o tempo de trabalho social médio necessário para produzi-la nas condições de produção socialmente normais.

A mercadoria é a unidade entre dois termos, o valor de uso e o valor de troca. Estes dois conceitos, no caso, o valor de uso e o valor de troca, correspondem a dois tipos de trabalho, o trabalho concreto e o trabalho abstrato, respectivamente. $\mathrm{O}$ trabalho concreto, que dá a especificidade do trabalho realizado e o trabalho abstrato, que expressa o dispêndio de trabalho em geral, em força humana geral, não específica, medido em tempo. O tempo de trabalho socialmente necessário é a combinação de valor de uso e de valor de troca, que por sua vez são resultados do trabalho concreto e do trabalho abstrato.

Nas escolas de economia dirigidas por Nahuel Moreno, o pensador e militante político argentino ensinava como Marx utilizava-se de Hegel para entender o conceito de medida, fundamental na definição do conceito de ser em Hegel e de valor em Marx. Em Hegel a medida é justamente a síntese da qualidade e da quantidade. Moreno explicava que um sujeito não pode ir ao armazém e pedir simplesmente açúcar: "quero açúcar", sem dizer quanto, é um pedido sem sentido. Da mesma forma não pode simplesmente dizer quero $1 \mathrm{k}$, sem dizer $1 \mathrm{k}$ do que. Então, a medida é unidade da quantidade e da qualidade. Assim, a mercadoria tem que ter qualidade e quantidade para ter medida. E o tempo de trabalho consiste justamente na medida de valorização do capital, isto é, quanto maior o tempo de trabalho socialmente necessário para a produção das mercadorias maior é seu valor.

$\mathrm{O}$ valor de uso e o valor de troca, o trabalho concreto e abstrato, se unem no conceito de mercadoria. $\mathrm{O}$ valor de troca representa o valor que tem como base material, como pressuposto ter valor de uso. Podemos dizer que mais uma vez aqui se expressa o

Procedimento dialético de Hegel, que separa teoricamente a totalidade do mundo da experiência imediatamente dado em pares de conceitos opostos para depois, da contraposição e união dos conceitos abstratos que se negam reciprocamente, voltar

\begin{tabular}{|c|c|c|c|c|}
\hline Rovista Dialectus & Ano 9 & n. 18 & Outubro 2020 & p. $86-101$ \\
\hline
\end{tabular}


novamente a esta totalidade concreta, agora, entretanto, como totalidade conceitual (KORSCH, 1979, p. 158).

Neste duplo aspecto da mercadoria está internalizada a contradição que irá se desenvolver em escala cada vez mais ampliada. A diferença entre o valor de uso e o valor de troca se converterá em contradição, e em oposição entre ambas, até chegar depois na contradição e até no antagonismo entre a mercadoria e o dinheiro.

Nesta contradição básica entre valor de uso e valor de troca está posta a primeira possibilidade da crise, embora as condições completas para a mesma ainda não possam se desenvolver no nível da produção simples.

O comprador passa a ter a mercadoria, o vendedor o dinheiro, isto é, uma
mercadoria que entra em circulação a qualquer tempo. Ninguém pode vender sem
que alguém compre. Mas ninguém é obrigado a comprar imediatamente, apenas por
ter vendido. A circulação rompe com as limitações do tempo, de lugar, e individuais,
impostas pela troca de produtos, ao dissociar a identidade imediata que, nesta
última, une a alienaçãa do produto próprio e a aquisição do alheio, gerando a
antítese entre venda e compra (MARX, 1987, p. 128).

$\mathrm{Na}$ ampliação da troca já está a possibilidade da crise. Afinal, com a separação entre o ato de venda e de compra está a possibilidade de que ao ato de venda não se suceda um de compra. Por algum motivo, qualquer que seja interrompida a circulação de mercadorias, teríamos um quadro de mercadorias inventáveis.

Uma questão mais deve ser dita. O conceito de valor, isto é, de tempo de trabalho socialmente necessário não é um conceito material. Trata-se de uma relação social. Não se pode ver a relação; ela pode ser representada pela mercadoria, mas o tempo de trabalho socialmente necessário não é a mercadoria $x$ nem $y$. Ele se estabelece a partir de uma relação social entre pessoas no processo de produção.

É interessante observar as repercussões da obra de Hegel também no conceito de dinheiro, sobretudo do dinheiro que se transforma em capital. Para usar os conceitos de Hegel, neste caso é quando a substância se transforma em sujeito que se automovimenta: "O movimento pelo qual adquire valor excedente é seu próprio movimento, sua expansão, logo sua expansão automática. Por ser valor, adquiriu a propriedade oculta de gerar valor. Costuma parir ou pelo menos põe ovos de ouro" (MARX, 1987, p. 185).

Até aqui nos limitamos as categorias iniciais de O Capital. Não vamos além. O que apenas insistimos é que a leitura está baseada no seguinte argumento.

\begin{tabular}{|l|l|l|l|l|}
\hline Rovista Oialectus & Ano 9 & n. 18 & Outubro 2020 & p. 86-101 \\
\hline
\end{tabular}


Uma vez dadas as categorias de base, toda a evolução do capitalismo, até a respectiva saída de cena, está já programada ao longo das contradições que decorrem da primeira. A contradição originária entre trabalho concreto e trabalho abstrato, entre valor de uso e valor, comporta o nascimento de formas novas, as quais, por seu turno, se revelam contraditórias, suscitando, portanto, outras formas novas, e assim por diante, num movimento aparentemente sem fim (JAPPE, 2006, p. 175).

Como explicou muito bem Karel Kosik (2011, p. 181), Marx sabe que a mercadoria é "a forma concreta do produto do trabalho", o "concreto econômico mais simples", "a forma celular", na qual "se contém, de modo oculto, não desenvolvido e abstrato todas as determinações fundamentais da economia capitalista" porque já havia estudado o capitalismo em sua totalidade, no seu conjunto de determinações desenvolvidas.

\begin{abstract}
A mercadoria pode servir de ponto de partida da exposição científica porque já se conhecia o capitalismo em seu conjunto. Do ponto de vista metodológico isto significa o descobrimento de uma conexão dialética entre um elemento e a totalidade, entre um embrião não desenvolvido e o sistema desenvolvido e em funcionamento. A legitimidade e a necessidade da mercadoria como ponto de partida da análise do capitalismo é demonstrada nos primeiros três livros de $O$ Capital, isto é sua parte teórica (KOSIK, 2011, 181).
\end{abstract}

Fica aqui claro que a demonstração do começo se encontra no conjunto da obra.

Nela veremos a odisseia da mercadoria, como se fosse o sujeito da história, vendo a estrutura do mundo capitalista tal como seu movimento real a cria, acompanhando suas leis de movimento, suas aparências e desdobramentos, que quer dizer também o desenvolvimento de suas contradições, que envolve não apenas a economia, mas a atividade social e política, a própria luta de classes. O conceito, neste caso o capital como relação social, se desenvolve através de contradições. Por isso veremos mais de perto algumas das categorias básicas e seus desdobramentos.

Sabe-se que Hegel começou sua exposição em a Ciência da Lógica pelo ser, o mais simples e abstrato, sem determinações. Como vimos, Marx descobriu a importância do conceito de valor e utilizou a categoria da mercadoria para constituir o todo a partir de sua expansão. O valor de troca historicamente surgiu antes do capital. Estava presente, conforme Marx, nos porões da sociedade burguesa. Foi um processo histórico que levou o valor de troca a ser incorporado em determinações mais complexas, a ir cumprindo um papel dominante com o desenvolvimento do próprio capitalismo. Trata-se da impressão de uma construção a priori, porque de fato Marx descortina o real a partir de uma exposição que vai do mais simples ao mais complexo e que, começando pela mercadoria, segue sua exposição pela expansão das determinações da própria mercadoria, num movimento que se desenvolve pelas

\begin{tabular}{|l|l|l|l|l|}
\hline Govista Dialectus & Ano 9 & n. 18 & Outubro 2020 & p. 86-101 \\
\hline
\end{tabular}


contradições contidas em seu interior. É começando sua exposição pelo abstrato que Marx, seguindo Hegel, defendeu que deveria ir-se construindo o concreto como um concreto pensado.

O imediato e mediato - a influência evidente de Hegel

A importância da abstração remete à discussão sobre o círculo do concretoabstrato-concreto. O concreto é o verdadeiro ponto de partida, dizia Marx. Parece concreto e real, objetivo, começar pelo estudo da população. Trata-se de quem realiza a atividade social. Mas como compreender a população? A população embora pareça ser o mais concreto, é uma abstração sem as classes sociais que a compõem. Por sua vez, é uma generalidade falar de classes sem referir-se às relações de propriedade, como é distribuído o produto social, o que envolve discutir o capital e o trabalho assalariado, o que supõe a produção de mercadorias, a troca, o dinheiro etc. Estas são lições de Marx que o levava a concluir que o começo pela população era apenas uma representação caótica do todo. (MARX, Grundisse, 2011)

Então, quando se começa a investigação temos a representação caótica do todo. O desafio é compreender este todo e para tanto é preciso analisar, separar, ou seja, é preciso começar abstraindo. Ao mesmo tempo, é preciso ver a conexão entre os processos, as leis internas do seu desenvolvimento. Para se chegar ao concreto pensado se necessita, se pressupõe a abstração. A percepção do objeto pelo sujeito já é uma primeira abstração que precisa se desenvolver para que o pensamento apreenda o concreto, reproduza o concreto como concreto pensado. O concreto pensado, sendo um resultado, é uma nova abstração para o desenvolvimento do pensamento, que vai do simples para o complexo, em totalizações mais ricas num processo de aproximação sucessiva do real. Abstrato e concreto são também, como tudo em Hegel, termos relativos, já que o concreto como resultado é o abstrato que serve de base para uma nova elaboração. Para tanto tem que fazer análises e separações, novas abstrações.

Lênin defendia esta posição com as seguintes palavras:

Hegel tem toda a razão no essencial contra Kant. O pensamento, subindo do concreto ao abstrato não se afasta - se ele é correto - (e Kant, como todos os filósofos, fala do pensamento correto) - da verdade, antes se aproxima dela. A abstração da matéria, da lei da natureza, a abstração do valor etc., numa palavra, todas as abstrações científicas (corretas, sérias, não absurdas) refletem a natureza mais profundamente, mais fielmente, mais completamente. Da intuição viva ao

\begin{tabular}{|l|l|l|l|l|}
\hline Qevista Dialectus & Ano 9 & n. 18 & Outubro 2020 & p. 86-101 \\
\hline
\end{tabular}


pensar abstrato e dele à prática - tal é o caminho do conhecimento da verdade, do conhecimento, da realidade objetiva (LÊNIN, 1989, p. 155).

Em seus cadernos filosóficos Lênin ainda cita Hegel aprovando a seguinte ideia:

\begin{abstract}
A lógica é a doutrina do conhecimento. O conhecimento é o reflexo da natureza pelo homem. Mas não é um reflexo simples, imediato, total, mas o processo de uma série de abstrações, da formação, da constituição dos conceitos, leis etc. E em seguida completa: "O homem não pode abarcar $=$ refletir $=$ representar a natureza toda, inteiramente, a sua "totalidade imediata", pode apenas perpetuamente aproximar-se disso, criando abstrações, conceitos, leis, um quadro científico do mundo etc., etc. (LÊNIN, 1989, p. 166).
\end{abstract}

Uma palavra a mais sobre a apreensão do real e a questão da abstração vale ser dita para percebemos como Marx utilizava a obra de Hegel e seu método. Sabe-se que Marx (2011) definia que era útil se referir à produção em geral, mas, ao mesmo tempo, deixava claro que era preciso avançar em suas determinações específicas para compreender a realidade concreta. Ele dizia que todas as épocas têm características em comum, determinações em comum e que a produção em geral é uma abstração, mas uma abstração razoável, na medida em que efetivamente destaca e fixa o elemento comum, poupando-nos assim da repetição.

Em outras palavras, a produção em geral não é a produção em seus momentos históricos, em sua concretude, em sua especificidade, mas há neste conceito, isto é na produção em geral, traços de todos estes momentos. O conceito de produção, contudo, exige uma aproximação do concreto via sua particularização. Esta era a convicção de Marx. É evidente que Marx adotou esta conclusão bebendo do método de Hegel, cujas palavras eram claras: "o conceito é um saber verdadeiro". E em seguida completava: "O conceito é o universal que se particulariza a si mesmo (por exemplo, o animal como mamífero, acrescenta isso à determinação exterior do animal)" (HEGEL, 1976, p. 29). Nas categorias de Marx a produção em geral se particulariza a si mesmo na produção capitalista.

E Hegel ainda explicava:

O fato de ser o pensamento não já abstrato, mas determinado, ao determinar-se a si mesmo, o resumimos na palavra "concreto". O pensamento se deu um conteúdo, tornou-se concreto, isto é, se unificou ao desenvolver-se. Donde se conceberam e se uniram inseparavelmente várias determinações na unidade (HEGEL, 1976, p. 29).

Ensinava, ainda, que a abstração do pensamento é o universal e o conceito o determinante de si, que se particulariza. E o particular, seguindo Marx, é o processo de

\begin{tabular}{|l|l|l|l|l|}
\hline Revista Dialectus & Ano 9 & n. 18 & Outubro 2020 & p. 86-101 \\
\hline
\end{tabular}


produção capitalista, o D-M-D'. De tudo o que foi dito, vale reformar que a obra econômica de Marx, embora tenha bebido da lógica de Hegel para compreender e expor o movimento de O Capital, não substancializava o lógico. Por isso, enquanto as categorias de Hegel eram filosóficas, as categorias em Marx, que são determinações do ser, eram econômicas e sociais.

Sua dialética não era o movimento abstrato do espírito, mas o movimento de forças econômicas e sociais, e mais especificamente o movimento - e, portanto, suas contradições - do regime do capital. Assim, a dialética de Marx foi muito diferente da dialética de Hegel, à medida que foi uma dialética materialista, cujos movimentos e a história não foram uma aplicação da dialética abstrata.

\section{Referências:}

CAMPOS, Lauro. A Crise Completa. São Paulo: Boitempo, 2001.

CHÄTELET, François. O Pensamento de Hegel. Lisboa: Editorial Presença, 1968.

FEURBACH, Ludwig. La Filosofia Del Futuro. Buenos Aires: Ediciones Calden, 1969.

HEGEL, G. W. F. Correspondance. Paris: Gallimard, 1963.

. Ciencia de la Lógica. Buenos Aires: Ediciones Solar y Libreria Hachette, 1968.

. Enciclopédia das Ciências Filosóficas em Epítome. Lisboa, Edições 70, 1969, v.

I.

Introdução à História da Filosofia. São Paulo: Hemus, 1976.

HEGEL, G. W. F. Propedêutica Filosófica. Lisboa: Edições 70, 1989.

“A Filosofia do Espírito". Enciclopédia das Ciências Filosóficas. São Paulo: Loyola, 1995.

Fenomenologia do Espírito. Rio de Janeiro: Vozes, 2002.

JAPPE, Anselm. As Aventuras da Mercadoria: Para uma nova crítica do valor. Portugal: Antígona, 2006.

KORSCH, Karl. Teoría Marxista y Acción Política. México: PYP, 1979.

KOSIK, Karel. Dialética do Concreto. São Paulo: Paz e Terra, 2011

LÉNINE, V. I. Obras Escolhidas. Lisboa: Edições Avante, 1989. Tomo VI.

MARX, Karl. Grundrisse. Buenos Aires: Siglo XXI, 1972.

Grundrisse. São Paulo: Boitempo, 2011.

O Capital. São Paulo: Bertrand Brasil/DIFEL, 1987, Livro I.

\begin{tabular}{|c|c|c|c|c|}
\hline Qovista Dialectus & Ano 9 & n. 18 & Outubro 2020 & p. $86-101$ \\
\hline
\end{tabular}


MARX, Karl; ENGELS, Friedrich. Correspondência Marx e Engels. Buenos Aires: Editorial Cartago, 1987.

Cartas Filosóficas e o Manifesto Comunista de 1848. Carta a Paul V. Annenkov. São Paulo: Moraes, 1987.

; ENGELS, Friedrich. A Sagrada Família. Rio de Janeiro: Presença, 1974.

; ENGELS, Friedrich. O Manifesto Comunista 150 Anos Depois. Rio de Janeiro: Contraponto, 1997.

MULLER, Marcos. Exposição e Método Dialético em "O Capital” Boletim Seaf, número 2, Belo Horizonte, 1982.

MORENO, Nahuel. Lógica Marxista e Ciências Modernas. São Paulo: Sundermann, 2007.

ROBAINA, Roberto. Marx e o núcleo racional da dialética de Hegel. São Paulo: AlfaÔmega, 2013.

\begin{tabular}{|c|c|c|c|c|}
\hline Q Revista Dialectus & Ano 9 & n. 18 & Outubro 2020 & p. $86-101$ \\
\hline
\end{tabular}

